\title{
Research on Intellectual Property Benefits Allocation Mechanism-Using Case of Regional-Development Oriented Collaborative Innovation Center of China
}

\author{
Duanyang Ren1,2, Xiaoyan Song 1,2, Haibin Zhou ${ }^{1,2}$ \\ ${ }^{1}$ School of Public Affairs, University of Science and Technology of China, Hefei, China \\ ${ }^{2}$ School of Economics and Management, Southwest University of Science and Technology, Mianyang, China \\ Email: rdy@mail.ustc.edu.cn
}

Received 8 July 2015; accepted 4 August 2015; published 7 August 2015

Copyright (C) 2015 by authors and Scientific Research Publishing Inc.

This work is licensed under the Creative Commons Attribution International License (CC BY).

http://creativecommons.org/licenses/by/4.0/

c) (7) Open Access

\begin{abstract}
The intellectual property (IP) benefits allocation is a major problem in collaborative innovation, because the collaborative partners have different benefits pursues, and they make the allocation of ownership and benefits complicated. If the interests can't be allocated properly, then the conflicts will occur between the collaborative partners and collaborative relationship can't last long, so we focus on the benefits allocation mechanism of IP to ensure each participated partner can get the benefits fairly. Some scholars noticed the importance of IP benefits allocation and conducted theoretical research, which provided model and theoretical analysis, but these research contents were not comprehensive, the research methods and evidences seemed inadequate, which leaded the conclusions into having limited meaning. Thus, we use case study and investigate regional-development oriented collaborative innovation center to examine the benefits allocation mechanism. We find out the problems in the existing benefits allocation mechanism, such as the compensation and rewards are not enough, the benefits allocation should be fair, the payment way is not various and so on. Based on the case study on the status quo and combined with related needs, we put forward that ensure the ownership of IP, attention on regulation construction, benefits protection and so on. We hope this study can solve these problems through case analysis, and benefit to maintain collaborative relationship.
\end{abstract}

\section{Keywords}

Collaborative Innovation, Benefits Allocation Mechanism, Collaborative Innovation Center, Intellectual Property, Case Study 


\section{Introduction}

As the competition intensifies, the cycle of technology innovation and product upgrade is getting shorter. Organization can't always rely on itself to complete innovation activity, thus these organizations are gradually tending to cooperate with others. Scholars usually regard that collaborative innovation organized by two or more organizations, involving knowledge sharing and technology transferring, generally the collaborative partners are not only firms, but also universities and research institution. According to practical experience, collaborative innovation is usually considered as a series of mechanisms, such as internal knowledge sharing and integrating mechanism. The participants have common goals which need modern information technology to build information exchanging institution, to let these participants provide and absorb knowledge and technology, so that they can achieve the goal of collaborative innovation [1].

Collaborative innovation has similarity with open innovation, but still there exists difference. Chesbrough (2003) put forward the open innovation model, it defined the organization could use resources from internal and external, and take advantage of these research achievements to reach commercialization [2]. During this process, the organization and collaborative partners are all getting benefits. But collaborative innovation has boundary limits and certain objects. Besides, the collaborative innovation varies in accordance with contexts, the participants include university, firms and research institution, and thus it should integrate different innovation elements and achieve added-value ultimately [3].

Our government already knew the importance of collaborative innovation, and made policy to support that strategy. Such as the Ministry of Education developed "2011" plan to implement the collaborative innovation strategy. Collaborative innovation center as the important carrier of collaborative innovation strategy is selected as our research objects. There are four types of collaborative innovation center, namely scientific technology oriented, culture-oriented, industry-oriented, and regional-development oriented. Different collaborative innovation centers have different missions and characteristics. We focus on the regional-development oriented collaborative innovation center to examine the IP benefits allocation mechanisms. This is because the achievement of this type collaborative innovation center not only has scientific research value, but also has commercial value, thus it is urgent to solve the problem caused by IP benefits allocation.

\section{Research Object and Methodology}

\subsection{Research Object}

We investigate some regional-development oriented collaborative innovation centers and select specific one to explore the IP benefits allocation mechanisms, which include ownership allocation based on collaborative contracts, the rights of benefits share, risk prevention mechanism and payment way. We investigate the status quo of these aspects and combined with investigated case data to solve the existing problems.

\subsection{Research Methodology}

\subsubsection{Literature Review}

We collect the research on collaborative innovation and intellectual property through library database, and to sort and summarize the literature research. We find the existing research achievements as the theoretical basis for our study.

\subsubsection{Survey Analysis}

We investigate some collaborative innovation centers to collect data and make record for the difficulties. We interview related staff and record their attitude about the benefits allocation, the related question includes: "what contains in your rewards?", "are you satisfied with what you got?", "do you think you have the rights if sharing the IP commercial benefits?”, etc. Thus we can find the problems in practice and these data could be support for our question.

\subsubsection{Case Study}

After collecting data, we select typical case to illustrate the current situation and problems of IP benefits allocation mechanism, enhance the reliability and validity. The purpose of case study is to describe, examine or generate new theory. If lacking systematic regression analysis or reliable data, case study is an effective method to 
examine the problem. This paper choose Jiangsu advanced biological and chemical manufacturing collaborative innovation center to explore the IP benefits allocation deeply, and come up with some suggestions for government to make policy usefully.

The reason we choose Jiangsu advanced biological and chemical manufacturing collaborative innovation center as the case study object is that, compared with other regional-development collaborative innovation centers, Jiangsu advanced biological and chemical manufacturing collaborative innovation center consist by many famous universities, firms and research institutions and approved in the first batch, which reflect the importance of this center. Besides, this center has good collaboration with foreign universities and has built comprehensive mechanisms to protect the benefits for the participated organizations. What's more, Jiangsu province has developed economy and this center faced biology technology and new material manufacture, thus the center focuses on market need and tends to commercialize the patent. Thus the ownership and benefits allocation issues highlight. So we explore the problems in IP benefits allocation mechanism and find out the real needs of research workers.

\section{Status Quo and Problems of the Collaborative Innovation Center Benefits Allocation Center}

\subsection{The Regional-Development Oriented Collaborative Innovation Center}

The regional-development oriented collaborative innovation center is government-led, in order to serve regional economy and social development. The mission is promoting the collaboration between universities and companies, to make this area being a leading position of technology innovation. This type of collaborative innovation center is built by government, based on the needs of market, it integrates the work of university, company and government sectors to promote technology transfer and area economy development.

We choose Jiangsu Advanced Biological and Chemical Manufacturing Collaborative Innovation Center as the representative case to study. Jiangsu advanced biological and chemical manufacturing collaborative innovation center was formed by Nanjing Technology University, Jiangsu Economy and Information Committee, Nanjing Government and Yangzi Petrochemical Company Limited (Figure 1). The center faces the demand for Jiangsu chemical industry, and focus on advanced technology and innovative products, it has four directions: manufacturing the chemical products, membrane material and manufacturing process, optoelectronic material and devices and manufacturing effective cementations materials. Besides it promotes collaborative innovation practice and institutional reform, try to be an important player in new material and chemical industry.

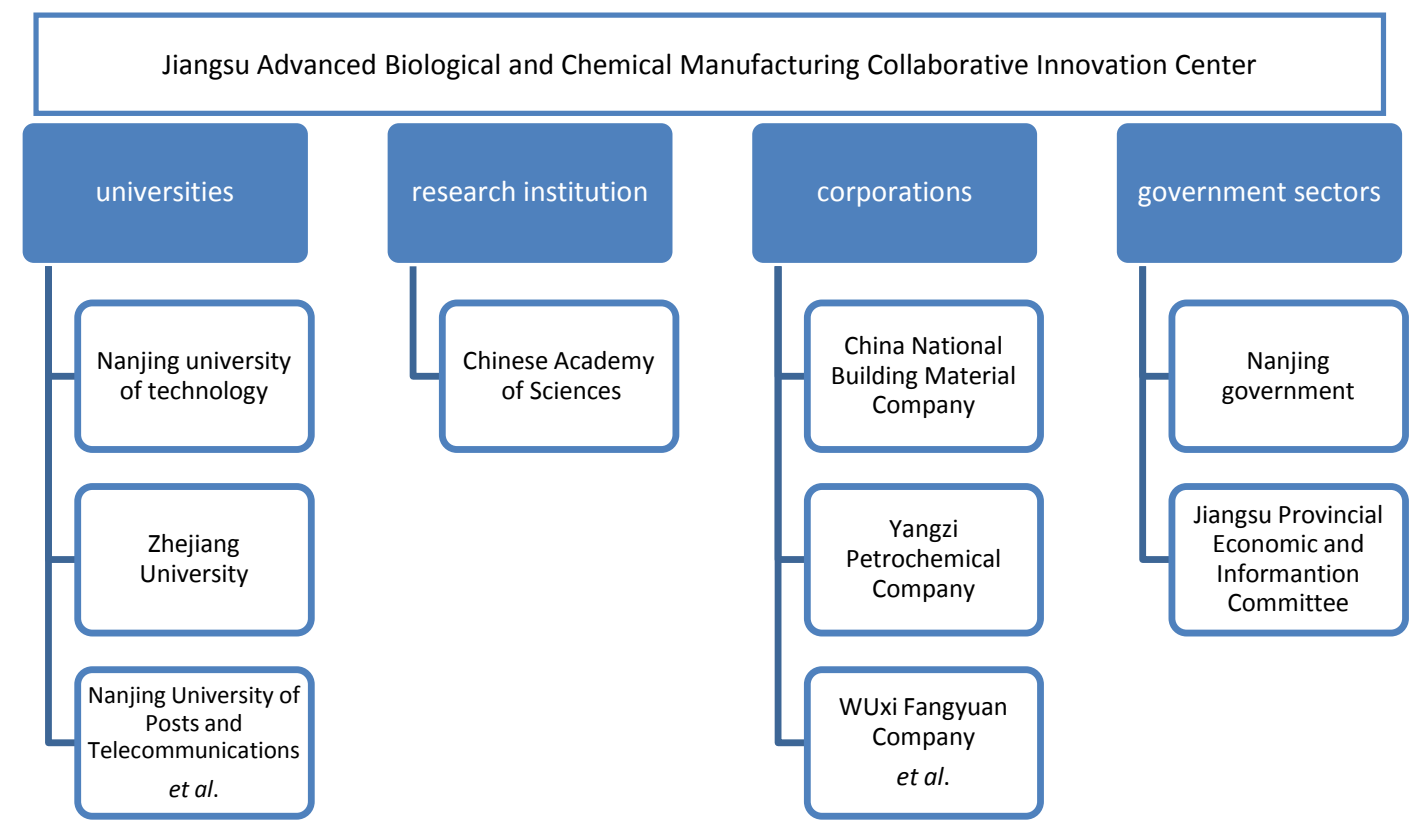

Figure 1. The formation of Jiangsu Advanced Biological and Chemical Manufacturing Collaborative Innovation Center. 
The implementation of this strategy brings challenge for the university in this district. The university and research institutions should change view to innovate institution mechanism and have practical achievements. This type centers have to face with major industry be government-guidance as well as company involving to integrate these elements. The center takes advantages of university, government and market, tries to build operation mechanism which government-led, the university and company participated to apply in practice. The target is to get breakthrough in new material research and energy conservation and emission reduction in manufacturing process. Besides, it is important to make technology commercialized and play demonstration and support role in regional development.

\subsection{Status Quo of IP Benefits Allocation Mechanism}

In these mechanisms of regional-development oriented collaborative innovation center, the specific programs funded by government support collaborative innovation activities priority, the government department funds the technology platform. Besides the government make policy for company-dominated collaborative innovation programs, the project participated by research institution and university to implement collaborative innovation strategy. The research achievements found by university, research institution and provincial government, within the first year when the project acceptance, the government encourages the project undertaker to gain economy benefits of IP achievements [4]. From the second year, transfer the un-commercialized IP achievements to provincial technology transfer agency. For the technology transformation which invested by shares, the participated research worker can enjoy at least $20 \%$ of the shares. If the IP technology was transferred to other organization, the participated research work can enjoy at least $20 \%$ of net income after tax. If the IP technology is implemented by the inventors or collaborated with others, the participated research worker can get $5 \%$ of net income after tax with 3 - 5 years, which after the project can bring benefits. If the project was funded by company and cooperated with university, which has the rest of research funds, the government allows transferring the money to registered funds of technology company, the participated research worker can enjoy $80 \%$ of registered funds, university can have the rest parts.

\subsection{Existing Problem of IP Benefits Allocation Mechanism}

\subsubsection{The IP Benefits Allocation between Universities, Research Institutions and Research Workers}

It is necessary to enhance collaboration between universities, companies and research institutions, distinguish the duty and responsibility of different collaborative partners. At the beginning stage, it is essential to sign contract for collaboration. Based on the contract, the participants can make sure the ownership of IP. The benefits conflicts occur in IP ownership, transformation and protection. In specific process, the participants should have complementary advantages and common benefits. When the university and company have different values, the conflicts occurs, which could lead the collapse of collaboration. The solution to this problem is making standards of benefits allocation, such as evaluating the participants' effort of innovation, matching with benefits. But it is difficult to do, which need to seek solutions from experience and practice. The participants should consider the benefits of the center, not only pursue their own interests, but also public interests. Besides it still need the institution protection and government guidance [5].

\subsubsection{The Rights of Research Worker Is Uncertain}

University and research institution have research worker, technology and facilities, so these organizations have advantages of research and undertake most part of research missions. The IP benefits allocation in university mainly involving school, department, research worker and management. As the research worker explore the innovation activity, it is important to inspire them, also it has directly impact on explicit knowledge in collaborative innovation and tacit knowledge transformation, thus it can influence the result of collaboration. So we should focus on the rights of research worker. But in the process of technology transformation, it is difficult to protect the research worker's rights. Because the IP ownership, which possessed by university is state-owned. This determines the IP can't be transferred casually. Besides, the IP transformation process is complicated, and the university can't allocate the IP benefits to research workers when the IP was invested as registered funds, even though the university has the IP ownership. In total, in the current system, the university and research in- 
stitution gain the benefits when the IP brings interests, but research worker doesn't gain too much interests, the rights of research worker should be protected.

\subsubsection{The Ways of Benefits Allocation Are Less}

Due to the reason noted earlier, inventors have no choice but accept these rewords as the compensation for their work, besides the standards of awards varies, it is difficult to implement in practice. Also there is no existing law to punish the company which does not comply with these awards regulations. Some rewards standards made by company below the policy required standards. These problem lead to the reward system cannot be implemented, the inventors' rights can't be protected, which result in the research work lost motivation.

\section{The Countermeasures for IP Benefits Allocation}

\subsection{Establishes the Perfect Laws and Regulations System}

Existing regulations on intellectual property intangibles are less specific, the government should guide the direction of collaborative innovation, coordinate the relationship between various participants and take advantage of university and research institution to do research work. In addition, the government should set policy on tax and finance to motivate the company and other service agency to participate in the collaboration, promote industrial upgrading through these policies. It can make the collaborative innovation direction match with the national development strategy and constrain the behaviors of participants to avoid opportunism. Therefore it can contribute to the sustainable development of collaborative innovation.

\subsection{Ensure the Ownership of IP Achievements}

Before allocating the IP benefits, the first step is making sure of IP achievements ownership, so that the center can allocate IP benefits fairly. The government can supervise and negotiate the collaboration process based on the principles of mutual benefit, profit sharing and risk compensation. The government should compare the deserved profits percentage with the invested resource, the inputs will have positive effects on profits shares. Moreover, the government should put the efforts into consideration, namely collaboration positivity and innovation performance [6]. The former means the attitude of the collaborative member participated in collaboration, the latter means the performance on technological innovation and knowledge transformation, the higher performance, the more efforts. Finally, the collaborative partners should undertake risk jointly, the risk including technological risk, market risk and cooperation risk. Thus, the government plays an important role in collaborative innovation.

\subsection{Protecting the Rights of Research Worker}

When the company gets IP achievements, it should also notice that the research worker has the rights to get awards and compensation. Having uniformed standards for salary and awards is helpful to IP benefits allocation. We should know that the patent law sets the minimum standards, company and research worker can make bargain within certain scope. Besides, the center should broaden the compensation channels, such as some scholars suggested that make technology-invested and technology options feasible, expand the calculate base of compensation and make sure the rationality. Thus it could provide maximum protection for research work, and inspire them to work more actively.

\subsection{Attentions on Secondary Innovation of IP}

For the second innovation if IP achievements, it depends on the collaboration is temporary or long-term strategy, if the former one, as the collaborative relationship is over, the secondary innovation achievement of IP should belong to university and research institution, but because the achievements based on the previous research, thus the company should have priority of use and right of pre-emption. If the latter one, the secondary innovation is continue the previous research, the allocation rule does not change. The secondary innovation of IP can also bring benefits, thus the participants should consider whether the IP can be explored continuously [7]. If so, these organizations should note it clearly in contract to avoid conflicts and ensure the development of collaborative innovation center. 


\section{Conclusion}

Collaborative innovation program is a new measure for the country's economic development, the collaborative innovation center should play an important role in the innovation strategy, but the IP benefits allocation mechanism is a determinant factor of collaborative innovation center. Thus this paper investigated Jiangsu Advanced Biological and Chemical Manufacturing Collaborative, found out the existing problems in the collaboration process and put forward some suggestions for the IP benefits mechanism. Only when the issues of IP ownership and usufruct are settled down reasonably, the benefits conflicts could be decreased, the collaborative innovation center could operate stably and thus the collaborative relationship could last long. As the improvement of IP benefits allocation mechanism, the trust between collaborative partners would be gradually enhancing, that was an effective way to promote the competitiveness of universities and companies, also it could enhance our national innovation ability and keep sustainable development of our society.

\section{Acknowledgements}

This work was supported by "Research on Intellectual Property Promoting the Construction of Hefei-WuhuBengbu Independent Innovation Pilot Area” (Soft Science Research Plan of Anhui Province), Project Number: 1402052002, Duration Time: 2014.01-2014.12.

\section{References}

[1] Chen, J. and Yang, Y.J. (2012) The Theoretical Foundation of Collaborative Innovation. Science Research, 2, 54-56.

[2] Chesbrough, H.W. (2003) Open Innovation: The New Imperative for Creating and Profiting from Technology. California Management Review, 3, 33-58.

[3] Xiong, L. and Sun, Y.X. (2011) Review on Collaborative Innovation-Based on Approach Perspective. Science and Technology Management Research, 4, 49-52.

[4] Yang, L.L., Cai, A.H., et al. (2012) Research on IP Coordination Mechanism in Collaborative Innovation Center. Technology Development and Countermeasures, 11, 34-36.

[5] Li, L.S. (1997) Research on Benefits Allocation Mechanisms on Collaborative Innovation. China Soft Science, 2, 3133. http://dx.doi.org/10.1007/BF02882185

[6] Liu, B.S. (2000) Research on “Industry-University-Research Operation” Integrated Model. Management World, 6, 25-27.

[7] Luo, W. and Tang, Y.H. (2001) Collaborative Innovation System Analysis. Science and Science Technology Management, 11, 35-42. 